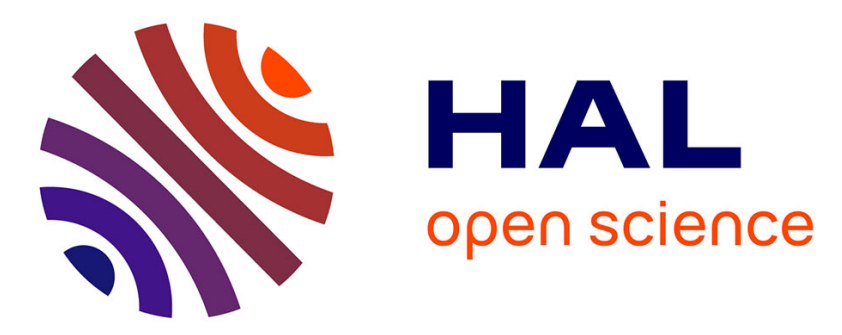

\title{
Vectorizing agrochemicals: enhancing bioavailability via carrier-mediated transport
}

\author{
Hanxiang $\mathrm{Wu}$, Hanhong Xu, Cécile Marivingt-Mounir, Jean-Louis \\ Bonnemain, Jean-François Chollet
}

\section{- To cite this version:}

Hanxiang Wu, Hanhong Xu, Cécile Marivingt-Mounir, Jean-Louis Bonnemain, Jean-François Chollet. Vectorizing agrochemicals: enhancing bioavailability via carrier-mediated transport. Pest Management Science, 2019, 75, pp.1507-1516. 10.1002/ps.5298 . hal-02115737

\section{HAL Id: hal-02115737 \\ https://hal.science/hal-02115737}

Submitted on 25 Jun 2020

HAL is a multi-disciplinary open access archive for the deposit and dissemination of scientific research documents, whether they are published or not. The documents may come from teaching and research institutions in France or abroad, or from public or private research centers.
L'archive ouverte pluridisciplinaire HAL, est destinée au dépôt et à la diffusion de documents scientifiques de niveau recherche, publiés ou non, émanant des établissements d'enseignement et de recherche français ou étrangers, des laboratoires publics ou privés. 


\section{Review}

\section{Vectorizing agrochemicals: enhancing bioavailability via carrier-mediated transport}

\section{Vectorizing agrochemicals via carrier-mediated transport}

Hanxiang $\mathrm{Wu}^{\mathrm{a}}$, Hanhong $\mathrm{Xu}^{\mathrm{a}}$, Cécile Marivingt-Mounir ${ }^{\mathrm{b}}$, Jean-Louis Bonnemain ${ }^{\mathrm{c}}$ and JeanFrançois Chollet ${ }^{\mathrm{b}, *}$

${ }^{a}$ State Key Laboratory for Conservation and Utilization of Subtropical Agro-bioresources and Key Laboratory of Natural Pesticide and Chemical Biology, Ministry of Education, South China Agricultural University, Guangzhou, 510642, Guangdong, China

${ }^{b}$ Institut de Chimie des Milieux et des Matériaux de Poitiers (IC2MP), Unité Mixte de Recherche CNRS 7285, Université de Poitiers, 4 rue Michel Brunet, TSA 51106, F-86073 Poitiers cedex 9, France

${ }^{c}$ Laboratoire Écologie et Biologie des Interactions, Unité Mixte de Recherche CNRS 7267, Université de Poitiers, 3 rue Jacques Fort, TSA 51106, F-86073 Poitiers Cedex 9, France

* Corresponding author: Tel. fax: +33 549453965

E-mail address: jean.francois.chollet@univ-poitiers.fr

E-mail addresses: wwhhxx33@126.com; hhxu@scau.edu.cn ;

cecile.marivingt.mounir@univ-poitiers.fr ; jean.louis.bonnemain@univ-poitiers.fr; jean.francois.chollet@univ-poitiers.fr 


\section{ABSTRACT}

Systemicity of agrochemicals is an advantageous property for controlling phloem sucking insects, as well as pathogens and pests not accessible to contact products. After the penetration of the cuticle, the plasma membrane constitutes the main barrier to the entry of an agrochemical into the sap flow. The current strategy for developing systemic agrochemicals is to optimize the physicochemical properties of the molecules so that they can cross the plasma membrane by simple diffusion or ion trapping mechanisms. The main problem with current systemic compounds is that they move everywhere within the plant, and this non-controlled mobility results in the contamination of the plant parts consumed by vertebrates and pollinators. To achieve the site-targeted distribution of agrochemicals, a carrier-mediated propesticide strategy is proposed in this review. After conjugating a non-systemic agrochemical with a nutrient ( $\alpha$-amino acids or sugars), the resulting conjugate may be actively transported across the plasma membrane by nutrient-specific carriers. By applying this strategy, non-systemic active ingredients are expected to be delivered into the target organs of young plants, thus avoiding or minimizing subsequent undesirable redistribution. The development of this innovative strategy presents many challenges, but opens up a wide range of exciting possibilities.

\section{KEYWORDS}

Agrochemical vectorization ; Propesticide ; Carrier-mediated transport ; Phloem transport ; Systemicity ; Plant transporters 


\section{INTRODUCTION}

Uptake, translocation, and distribution of agrochemicals in plants play important roles in determining the biological activity, off-target toxicity, and side effects of those molecules., ${ }^{1,2}$ An active ingredient has to overcome a number of obstacles before reaching its site of action. Bioavailability of an agrochemical product can be defined as the fraction of the dose of active ingredient applied to the plant (aerial parts or root system) that reaches the target site to exert its biological action, and the rate at which the process takes place. When applied by foliar spraying, the first barrier that plant protection compounds must cross is the plant cuticle. This is a complex route due to the variability of the cuticular composition, which can depend on many parameters, such as species, stage of development, or certain environmental conditions. This subject has already been extensively discussed elsewhere and the reader will thus be able to refer to several reviews. ${ }^{2-4}$

The plant plasma membrane is the second physical barrier to the absorption and distribution of agrochemicals. This lipid bilayer is a hydrophobic barrier that separates the cytoplasm (symplasm) from the cell wall and intercellular space (apoplasm) and therefore controls the exchange of information and substances between the cell and its environment. It is well known that systemic agrochemicals transported in plant vascular tissues must cross the cell plasma membrane at least once to enter the xylem and phloem conducting cells. Therefore, the mechanism of membrane permeation is a key factor for both the long-distance transport and distribution of agrochemicals in plants. Phloem mobile insecticides and fungicides have been proposed to be efficient in controlling piercing and sucking insects, especially if they attack the root system and the shoot, as well as root and vascular 
pathogens. ${ }^{5-7}$ However, only a limited number of current insecticides and fungicides exhibit a high phloem systemicity, e.g., spirotetramat and fosetyl-Al.

The movement of active ingredients from the site of application to the biochemical target can be significantly influenced by the systemicity of agrochemicals in plants. Many approaches have been employed to enhance the systemicity of agrochemicals in plants during both the discovery phase and the field use. ${ }^{3,5-7}$ As our understanding of transmembrane transport mechanisms increases, we can begin to think about new strategies to improve the bioavailability of agrochemicals in plants. The vectorization of an agrochemical compound consists in modulating and controlling the distribution of an active ingredient within the plant by associating it with a vector. In the case of molecular vectorization which is discussed in this review, the vector group will be introduced into a biologically active compound and the resulting molecule will be a propesticide. ${ }^{8}$ Once the molecule reach the target, it will release the parent molecule by the action of various enzymes or by a chemical hydrolysis.

In most cases, pesticides are transported across biological membranes through passive diffusion or ion-trapping mechanisms. In addition, it has been known for about three decades that some small agrochemical molecules are transported by plant plasma membrane transporters (Fig. 1). ${ }^{9}$ This indicates that the specificity of these transporters is not strictly limited to their physiological substrates, as is the case for drugs..$^{10}$ In the pharmaceutical field, some transporters are widely acknowledged as important determinants of pharmacokinetics and, in many cases, are critical for the entry of certain drugs into target organs. ${ }^{11}$ Prodrug strategies have been developed to improve drugs absorption and distribution via specific membrane transporters. ${ }^{12}$ 
Historically, passive diffusion was believed to be the dominant route for agrochemical uptake and transport. Thus, the first approach taken to improve systemicity was through optimizing the physicochemical properties of active ingredient to increase passive membrane penetration. ${ }^{7}$ However, the carrier-mediated process, which has attracted considerable attention in pharmaceutical development, should not be ignored by agrochemical research. The carrier-mediated xenobiotic uptake approach may also provide a new method to design agrochemicals to achieve site-specific delivery by utilizing plant membrane transporters. In this review, we highlight the possible role of plant transporters in optimizing the systemicity of agrochemicals, and this can lead to a vectorization strategy to improve their bioavailability and possibly to minimize accumulation on the parts of the plants consumed by vertebrates and pollinators.

This manuscript is divided into four major parts. (1) First, the successful prodrug strategies for enhancing the bioavailability of drugs via membrane transporters including peptide, amino acid and glucose transporters are briefly described. The same strategies can extend to agrochemical development to achieve site-targeted distribution. (2) Secondly, a brief overview of the carrier-mediated uptake of some systemic agrochemicals currently in use (fosetyl-Al, glyphosate, paraquat and 2,4-D) is given. (3) Thirdly, some attempts of carriermediated propesticides that are recently designed to be translocated by plant sugar and amino acid transporters are reviewed. Long-distance transport and release of the active ingredient are also addressed in this part. (4) Finally, the advantages and disadvantages of carrier-mediated propesticide strategies are discussed and we propose possible applications of a carriermediated strategy to develop phloem systemic pesticides and other types of agrochemicals. 


\section{Carrier-mediated prodrug strategy for enhancing bioavailability of agrochemicals}

Enhancing bioavailability of xenobiotic molecules is very important for both modern pharmaceuticals and agrochemicals, which are required to effectively translocate to sites of action while limiting side effects. The crucial role of membrane transporters in drug absorption, distribution, metabolism and elimination (ADME) has been widely recognized and their considerable pharmacological significance has been well described in several reviews. $^{11,13,14}$ There are more than 400 membrane transporters belonging to two major superfamilies: the solute carrier (SLC) transporters and the ATP-binding cassette (ABC) transporters. ${ }^{13}$ The drug transporters that are expressed in various epithelial barriers have received greater attention, particularly in the epithelia of the intestine, liver, and kidney, as well as the endothelium of the blood-brain barrier (BBB). ${ }^{14,15}$

By utilizing some membrane transporters, a prodrug strategy (Fig. 2) has been developed to achieve drug targeting to specific organs. ${ }^{16,17}$ In this case, a prodrug can be designed to conjugate with endogenous substrates, so that specific membrane transporters can recognize and transport the resulting prodrug molecules. There have been several successful developments in the pharmaceutical field, including peptide, amino acid and glucose transporters. For instance, the prodrug strategy targeted to the intestinal human peptide transporter 1 (PEPT1) has been applied to two antiviral drugs with low oral bioavailability, acyclovir and ganciclovir. In this example, the commercialized L-valyl ester prodrugs, valacyclovir and valganciclovir, are actively transported by PEPT1, which results in enhancement of the intestinal permeability of the parent drugs by 3 - to 10 -fold. ${ }^{18,19}$ The L- 
type amino acid transporter 1 (LAT1), expressed in the apical and basolateral membranes of the cells in the $\mathrm{BBB}$, is involved in the transport of neutral L-amino acids across the $\mathrm{BBB}{ }^{16}$ Thus, LAT1 has been utilized as a prodrug carrier to deliver amino acid-drug conjugates into the brain, for example, L-lysine conjugate of ketoprofen. ${ }^{20}$

The propesticide concept has been successfully applied in the design of agrochemicals for a long time. ${ }^{8}$ The catalogue of propesticides and their significance in improving biological activity and target selectivity have been comprehensively described in excellent recent

reviews. ${ }^{8,21,22}$ Contributions of propesticides to improve bioavailability by enhancing plant or insect uptake are also acknowledged, which mainly focused on optimizing the physicochemical properties to improve water solubility and lipophilicity of the parent active ingredient. $^{8,23,24}$ However, the design of a propesticide with greater bioavailability is still challenging and there is a lack of well-established strategies to achieve this. Prodrug approaches for enhancing the bioavailability of pharmaceutical drugs have set a good example for the agrochemical field. The same strategy may provide a new way for rational agrochemical design to increase the pesticide efficiency and reduce pesticide use. In particular, carrier-mediated processes could be a promising new approach to enhance the uptake of agrochemicals and improve their site-targeted distribution by utilizing plant membrane transporters.

\section{Carrier-mediated transport of agrochemicals in plants}

Plant plasma membrane transporters play a central role in the exchanges of information and substances between cells, organs and their environment. For instance, the transport of 
ions, carbohydrates, amino acids, peptides, hormones, secondary metabolites and xenobiotics can be regulated by a great variety of plant transporters. ${ }^{25-27}$ Two major transport systems are involved in the selective permeability of organic compounds: directly energized primary active transport by plant $\mathrm{ABC}$ transporters ${ }^{26}$ and $\mathrm{H}^{+}$-gradient-dependent secondary transport systems via $\mathrm{H}^{+}$-symporters. ${ }^{27}$ However, the role of plant transporters in local and longdistance transport of agrochemicals is still poorly studied.

Over the last three decades, a few agrochemicals have been found to be transported by identified plant carrier systems (Fig. 1). Glyphosate, a widely used herbicide, is translocated to root and shoot growing tissues via phloem after foliar application. ${ }^{28}$ Carrier-mediated uptake of glyphosate at low concentration has been reported in leaf protoplasts of broad bean via a phosphate transporter. ${ }^{29}$ In maize and soybean cell suspensions, active uptake of glyphosate was inhibited by carbonyl cyanide m-chlorophenyl hydrazone (CCCP), orthovanadate, diethylstilbestrol (DES), phosphate, and phosphonoformic acid (PFA), suggesting that the glyphosate carrier is a phosphate transporter energized by the plant plasma membrane $\mathrm{H}^{+}$-ATPase. ${ }^{30}$ One possible glyphosate-resistance mechanism is the nonrecognition of the active uptake carrier system, because the inhibition of glyphosate-loading into the phloem was observed in some glyphosate-resistant weeds. ${ }^{31}$ Furthermore, a recent study shows that L-type amino acid transporters (LAT1/LAT2) play major roles in the uptake of glyphosate across mammalian epithelial tissues. ${ }^{32}$ Phosphite, the active metabolite of fosetyl-Al, is a highly ambimobile fungicide. ${ }^{33}$ This agrochemical which can also be used as a fertilizer and weedicide is translocated by both high- and low-affinity phosphate transporters. $^{34}$ 
Two other herbicides, paraquat and 2,4-D, are transported by carrier-mediated processes. The uptake of paraquat into maize root cells and maize suspension cells was competitively inhibited by putrescine, indicating that a polyamine transporter is responsible for the uptake of paraquat. ${ }^{35}$ Two transporters involved in paraquat uptake by Arabidopsis tissues have been identified recently, namely polyamine transporter RMV1 (protein Resistant to Methyl Viologen 1), a member of the L-type amino acid transporter (LAT) family ${ }^{36}$ and AtPDR11 (Arabidopsis thaliana Pleiotropic Drug Resistance 11 transporter), a plasma membrane-localized $\mathrm{ABC}$ transporter, from the paraquat-tolerant mutant pqt24-1. ${ }^{37}$ The enhanced paraquat tolerance of pqt24-1 is due to loss of AtPDR11, which results in less accumulation of paraquat in plant cells. The uptake of the auxinic herbicide 2,4-D in maize root protoplasts occurs by two mechanisms, the ion-trap mechanism and active transport mediated by an auxin carrier. ${ }^{38}$ Moreover, the aromatic and neutral amino acid transporter ANT1 can also transport 2,4-D through the plasma membrane. ${ }^{39}$

\section{Carrier-mediated propesticide strategies for improving agrochemical systemicity}

Agrochemical systemicity can positively influence the biological performance of active ingredients. For example, ambimobile insecticides can be used to control hidden and soil living sucking pests after foliar application. ${ }^{40}$ The phloem movement of herbicides enables translocation to meristem tissues for control of weeds. ${ }^{41}$ Optimizing the physicochemical properties of active ingredients was considered an important way to improve diffusion through the plasma membrane and the systemicity of molecules in the discovery stage. 
Passive diffusion can be estimated by the physicochemical properties of agrochemicals such as lipophilicity, charge, and molecular size. Several simple rule-based models and mathematical models have been developed to predict and assess the membrane permeability of agrochemicals in the early-stage of pesticide discovery. The first two models used to

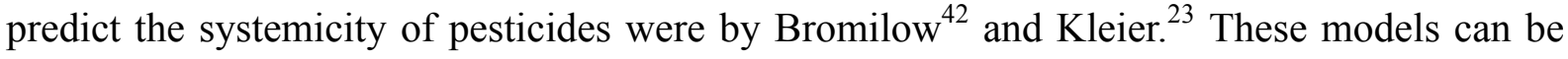
applied for both nonionized and acidic compounds by the combination of acid dissociation constant $(\mathrm{Ka})$ and 1-octanol-water partition coefficient (Kow). More recent models include additional parameters, especially the impact of the cuticle on pesticide uptake. ${ }^{43}$ In drug discovery, oral bioavailability or passive membrane permeability of drug candidates can be predicted using Lipinski's rule of five $(\text { Ro5 })^{44}$ and other simplified rules established by Veber. $^{45}$ The same approach was adopted to profile agrochemicals for screening and optimization. ${ }^{46,47}$ It should be noted that all those rule-based and mathematical models for passive diffusion are not applicable to active carrier-mediated molecules. ${ }^{47-49}$ Carriermediated processes can be considered a promising new strategy to overcome membrane barriers via conjugation of a pesticide with a nutrient.

It is well known for a long time that plant tissues synthesize many conjugates, such as hormone conjugates as mentionned before. ${ }^{50}$ For instance, indole-3-acetic acid (IAA) is stored in various protected forms, notably IAA-amino acid conjugates and IAA-sugar conjugates. The hydrolysis of most of these compounds during germination leads to release of free IAA. Using plant tissue cultures, it has been shown that synthetic IAA-amino acid conjugates can release auxin at different rates depending on their molecular structure. ${ }^{51}$ Over the last three decades, there have been several attempts to improve agrochemical systemicity or 
translocation to the root system using carrier-mediated xenobiotic strategy, designing conjugates with amino acid or glucose promoieties. Two synthesized $\alpha$-amino acid conjugates, lysine-2,4D (Lys-2,4D) and aspartic acid-triazolyl alcohol (Fig. 3, E6 ad E3 respectively), were pioneering in this area. ${ }^{52}$ In contrast to natural IAA-amino acid conjugates where the carboxylic group of auxin is covalently bonded to the amine function of the nutrient, these two conjugates exhibit a free $\alpha$-amino acid function. They markedly and specifically inhibited threonine uptake and phloem loading by leaf tissues, suggesting that both conjugates are recognized by amino acid transporters (Fig. 3) ${ }^{52}$ Further study using several derivatives of phenoxyalkanecarboxylic acid and L-lysine demonstrated that the plant amino acid carrier systems are able of recognizing and translocating a wide range of conjugates of various sizes, structures and Kow (Table 1$).{ }^{50}$ In the Ricinus system, the parent compounds were quickly released from these conjugates at various rates, except the 2,4-DB derivative E which remains undissociated (Fig. 4). ${ }^{53}$ Interestingly, the distribution study of the conjugate Lys-2,4D (MW $=349.21 \mathrm{Da})$ and 2,4-D on broad-bean shows that they were accumulated to significantly different extents in plant organs. ${ }^{9}$ During the first hours of long distance transport, the accumulation of Lys-2,4D in the root system is 5 to 10 times higher than that of 2,4-D after foliar application of the two compounds. ${ }^{9}$ Over time, Lys-2,4D progressively splits into 2,4-D and Lys, displaying 2,4-D herbicidal damage. Tryptophan and phenylalanine act as competitors for Lys-2,4D uptake, but not Lys or the other amino acids tested, suggesting that a specific amino acid transporter is involved in the preferential uptake of this conjugate. ${ }^{9}$

Further studies provided evidence that the sugar and amino acid carrier systems of 
plants are able to recognize and translocate conjugates dramatically larger than their natural substrates. Although no longer on the market, the fungicide fenpiclonil was chosen as a model molecule because its structure offers numerous possibilities to graft various functional groups. Conjugation of fenpiclonil with L-amino acids confered phloem mobility to this contact fungicide (Table 2). ${ }^{54,55}$ The phloem systemicity of the resulting conjugates was governed by a stereospecific amino acid carrier system and the bioavailability was dependent on the spacer arm structure. ${ }^{54}$ While the acidic derivatives of fenpiclonil were only taken-up at $\mathrm{pH}$ values near 5.0, the amino acid conjugates exhibited phloem systemicity for the whole range of foliar apoplast $\mathrm{pH}$ values (5.0 to 6.5$).{ }^{55}$ In contrast, glucose-fenpiclonil conjugate (D-GFC) is hardly detectable in the Ricinus phloem sap (Table 2). Contrarily to the thiol reagent $p$ chloromercuribenzene sulfonic acid (PCMBS) that binds to several intrinsic proteins, D-GFC specifically inhibits the activity of the sucrose carrier system involved in phloem loading in the Ricinus model and is therefore considered as a new tool in plant physiology. For instance, D-GFC allows the quantification of the two routes (apoplasmic and symplasmic) involved in the sucrose phloem loading in Ricinus seedlings after endosperm removal. ${ }^{56}$

Carrier-mediated propesticide strategies were also successfully extended to insecticides to design guided pesticides. ${ }^{57}$ Glucose and amino acid promoieties were introduced into insecticides to develop phloem-targeted proinsecticides (Table 2). The resulting derivatives included glycinyl fipronil conjugate ${ }^{58}$, sugar-fipronil conjugates, ${ }^{59,} 60$ D-glucose-rotenone conjugates, ${ }^{61}$ glycinergic-fipronil conjugate, ${ }^{62}$ and amino acid-chlorantraniliprole conjugates. ${ }^{63}$ Despite their parent compounds lack of mobility in the phloem, several of the above mentioned insecticide conjugates had good phloem systemicity., ${ }^{59,63}$ The vacuolar 
sequestration of sugar and glutathione conjugates via $\mathrm{ABC}$ transporters which occurs in planta during the final detoxification process of agrochemicals ${ }^{64}$ may reduce the phloem loading of these synthetic conjugates. Data from short time experiments using a fluorescent insecticide sugar conjugate indicate that the dye accumulates dramatically in epidermal cells and phloem, more specifically in sieve tubes after incubation of Ricinus cotyledons in an incubation solution containing N-[3-cyano-1-[2,6-dichloro-4-(trifluoromethyl)phenyl]-4[(trifluoromethyl)sulfinyl]-1H-pyrazol-5-yl]-1-(2-[N-(7-nitrobenz-2-oxa-1,3-diazol-4yl)amino]-2-deoxy- $\beta$-D-glucopyranosyl)-1H-1,2,3-triazole-4-methanamine $\quad$ (2-NBDGTF). ${ }^{60}$ The fluorescence in the mesophyll cells is moderate and localized mainly at their external part. Therefore, there is no clear evidence of an accumulation of 2-NBDGTF in the vacuoles under these experimental conditions. However, as the vacuome is the largest compartment of mesophyll cells, long-time experiments would be appropriate to specify the capacity of vacuoles to take up fipronil conjugates using both tissues and isolated vacuoles. Systemicity studies showed that the uptake of glucose-fipronil by cotyledon discs was markedly inhibited by carbonyl cyanide 3-chlorophenylhydrazone (CCCP), glucose, and phloridzin, and its phloem mobility was inhibited by phloridzin, suggesting that a carrier-mediated mechanism was involved in uptake and phloem loading. ${ }^{48}$ In addition, endogenous $\beta$-glucosidases were involved in the hydrolysis of a glucose-fipronil conjugate with an $O$-glycosidic bond, which can achieve the enzymatic release of the active aglycone. ${ }^{65}$ The enzymatic deglycolysation in vitro can be modulated by adjusting the linker length of the conjugate, and the in vivo insecticidal bioassy supports that the active aglycones are released from the conjugates after root absorption and exhibit the same level of activity as fipronil. ${ }^{66}$ Several attempts mentioned 
above suggest that the carrier-mediated propesticide approach of conjugation with a nutrient moiety is a feasible approach to confer systemic properties to non-mobile agrochemicals.

\section{Challenges of carrier-mediated propesticide strategies and perspectives}

Developing carrier-mediated propesticides is still in the initial stage. Because of the limited knowledge of the functional and structural characteristics of various plant nutrient transporters, searching for specific membrane carriers which can serve as targets for the active transport of agrochemicals is quite difficult. It requires considerable knowledge of their tissue distribution, expression level, and substrate specificity. Potential transporters for propesticide delivery should have a relatively high capacity and broad substrate specificity, which enable recognition and transport of a wide range of molecules without marked influence on the circulation of phloem sap. Plant carrier systems for sugars, amino acids and oligopeptides are considered possible targets for propesticide and other conjugate designs due to their expression and functional role in plant tissues. The broad substrate specificity of some of them (for example the Arabidopsis thaliana sucrose transporter, AtSUC2 ${ }^{67}$, A. thaliana lysine histidine transporter, AtLHT1 ${ }^{68}$ and Ricinus communis monosaccharide transporter, RcSTP $1^{69}$ ) supports the carrier mediated propesticide strategy.

This strategy may have the advantage of reducing the risk of pesticide residues exposure for a variety of organisms. Current systemic pesticides can be continuously redistributed during plant development to new tissues such as flowers, fruits, seeds and tubers, and this can lead to the exposure risk for pollinator insects as well as humans despite their low or moderate 
phloem mobility. This redistribution within plants can be restricted when non-mobile parent molecules are selected for linkage with a nutrient. After the conjugate is transported over long distances and released the active parent molecules in target tissues, the redistribution of the non-mobile parent molecules will be restricted, so that they can be retained in these tissues. In this case, the contamination of new growing edible parts will be prevented or minimized.

Taking into account these possible advantages, the carrier-mediated strategy for agrochemicals has been initiated during the last decades. However, up to now an extremely small number of research teams work in this domain. Its development involves a succession of several steps with many constraints that have probably discouraged researchers: (1) synthesis of a conjugate combining a non-systemic agrochemical with a small nutrient molecule that can be recognized and handled by plasma membrane carriers involved in phloem loading. This implies that the structure of the selected agrochemical compound should have possible reaction sites to easily graft a nutrient as well as having an essential functional group for substrate recognition and binding by nutrient transporters;.(2) recognition and translocation of the synthesized conjugates by carrier systems into the symplasm after application; (3) long-distance transport to target sites and unloading in sink tissues of young plants; (4) release of non-mobile parent compounds in these tissues and non-significant redistribution to newly developed organs used as food for humans, animals or pollinators; (5) safety assessment for users and the environment; (6) one point must be borne in mind is that for an agronomic application, the cost of the active ingredient should be economically acceptable.

Several conjugates have been successfully synthetized using various pesticides 
(herbicides, a fungicide and insecticides) and nutrients (amino acids and glucose) (Tables 1 and 2, Fig. 2). Most of these conjugates exhibited various levels of phloem systemicity in Ricinus seedlings, suggesting that they may be specifically recognized by plasma membrane carriers (Tables 1 and 2, Fig. 4). Many of these conjugates were still in the first and second above-mentioned steps of development. Only a few conjugates have undergone systemicity evaluation in intact plants (Table 2) and were able to translocate over long-distances from the point of application to release the parent compound (Table 2). ${ }^{9}$ Furthermore, two conjugates accumulated in plants against their concentration gradient, ${ }^{9,63}$ which may allow a lower dose to achieve the same biological activity. In addition, changes in the spacer arm structure may improve systemicity or cleavage of the conjugates (Table 2). ${ }^{55,70}$ However these results have been obtained from incidental modifications rather than intentional design. Therefore, there is another challenge that should be considered in the discovery and development of carriermediated propesticide. Unfortunately, in many cases the addition of nutrient promoieties to a parent compound can lead to undesirable reductions of biological activities. This means that there must be a biodegradable linker between promoiety and parent compound to facilitate bioactivation. The rational design of the spacer arm can affect the stability, selectivity and toxicity of propesticides. However, little work has been done in this area to explore a degradable spacer group.

Recent progress in molecular biology has greatly improved our understanding of the distribution, physiological function, and specificity of plant transporters. The methods based on expression-cloning techniques seem to be powerful tools to study the pesticide-transporter interactions. Various technologies to identify and characterize plant transporter functions have 
been reviewed elsewhere, ${ }^{71}$ which could also be used to study the carrier-mediated transport of agrochemicals. Heterologous expression of the selected transporter in different systems, ${ }^{71}$ such as yeast, Xenopus oocytes or cell lines of plant tissues provide effective tools to investigate the transporter specificity for existing and new candidate agrochemicals. In addition, several well-characterized plant models can be used to conduct in vivo studies of carrier-mediated processes of agrochemicals, such as Ricinus seedlings ${ }^{49}$ and transporter-gene knockout mutants of Arabidopsis.

Computational modeling represents a promising way tool to study the substrate affinity of transporters, evaluate the drug-transporter interactions and optimize the transporterdirected drug design. ${ }^{72}$ Two major techniques used to develop models have been well described, ${ }^{72}$ including ligand-based methods such as quantitative structure-activity relationship (QSAR) modeling and protein-based methods which generate the threedimensional structure of transporters. This new in silico approach has been used to investigate and predict how small molecules interact with plant transporter proteins. Homology models for four nitrate/peptide transporters (NPF) were built to investigate the substrate specificity of glucosinolates and cyanogenic glucosides. ${ }^{73}$ To analyze the binding of phloem-mobile coumarin esculin to the AtSUC2 transporter, structural modeling of the AtSUC2-binding pocket demonstrated some important structural requirements for recognition and transport of coumarin glucosides. ${ }^{67}$ However, the application of computational modeling is limited by the availability of crystal structure of plant transporters.

Preliminary experiments suggest that this conjugation strategy could be applied usefully to molecules involved in plant defense, even if they are mobile in the vascular system. For 
instance, it has been known for a long time that salicylic acid (SA) is a phloem mobile molecule. ${ }^{74}$ Its amount increases in the phloem sap in response to biological stresses but returned rapidly to initial level due to its ability to form inactive conjugates, notably by glycosylation and compartmentation in the vacuole, in addition to transcriptional regulation of its synthesis. ${ }^{75,76}$ After mature leaf inoculation by a pathogen, SA and glucosylsalicylic acid accumulate in the apical part of the shoot but not or marginally in the root system, ${ }^{77}$ therefore exhibiting an allocation pattern different from those of nutrients (sugars and amino acids) and amino-acid conjugates of various sizes which move both downward and upward in phloem. ${ }^{9}$ 58 In the Ricinus model, the Lys-SA conjugate accumulates in the phloem sap and is transported over a long distance as its unchanged form, at least in short time experiments, (Fig. 4, compound F). Under the same experimental conditions, the Lys-3,5-dichlorobenzoic acid conjugate is translocated in the phloem and exhibits a very weak metabolism to release 3,5-dichlorobenzoic acid (3,5-DCBA) (Fig. 4, compound G) which is a potent elicitor of plant defenses, even at low concentrations. ${ }^{78}$ This could allow accumulation of this conjugate in specific sink organs (including roots) and sink tissues (primary and secondary meristems, phloem and xylem parenchyma and other parenchymas which exhibit high metabolism activities), followed by a slow release of the mobile 3,5-DBCA. The ideal next step would be the induction of the long term protection against pathogens during plant development without the risk of phytotoxic effects. Considering (1) the limitation of the use in field of defense activators (such as acibenzolar-S-methyl and 2,6-dichloroisonicotinic acid) due to their phytotoxic effects when excessive doses are applied; ${ }^{78}(2)$ the high phloem mobility of LysSA and Lys-3,5-DCBA; (3) the ability of amino-acid conjugates to be translocated both to the 
root system and the apical part of the shoot, and (4) the very low metabolism of Lys-3,5DCBA which may extend its biological activity, this topic needs further development.

\section{Conclusions}

As mentioned above, several carrier-mediated conjugates have been successfully designed, which show interesting transport properties in plants. Similar to the carriers involved in prodrug uptake in animal and human organs, it is fascinating that plant plasma membrane transporters can translocate halogenated conjugates with a glucose or an $\alpha$-amino acid functional group that are dramatically larger (up to about $650 \mathrm{Da}$ and even about $850 \mathrm{Da}$ if fluorescent conjugates are taken into consideration) than the natural nutrients. This property offers wide development prospects. However, the question about which specific membrane transporters can be ideal targets for carrier-mediated strategy is still difficult to answer at the present time. To achieve the rational propesticide design targeting specific membrane transporters, additional efforts are required to improve our understanding of the carrier proteins, including expression, substrate specificity, and the mechanism of substrate recognition and translocation. The impact of plant transporters on other aspects of agrochemical absorption, distribution, metabolism and compartmentation which may influence resistance and environmental behavior, needs future investigations. The carriermediated propesticide strategy provides a promising way for vectorizing agrochemicals and various molecules involved in plant defenses by taking advantage of plant membrane transporters, which may result in higher bioavailability, greater efficacy (pesticides) or durable benefit (defense molecules) and lower non-target toxicity. The development of this 
innovative strategy presents many challenges, but opens up a wide range of exciting perspectives for the discovery of new products for a more sustainable plant protection.

\section{References}

1. Aajoud A, Raveton M, Aouadi H, Tissut M and Ravanel P, Uptake and xylem transport of fipronil in sunflower. J Agric Food Chem 54:5055-5060 (2006).

2. Wang CJ and Liu ZQ, Foliar uptake of pesticides - Present status and future challenge. Pestic Biochem Physiol 87:1-8 (2007).

3. Castro MJL, Ojeda C and Fernandez Cirelli A, Advances in surfactants for agrochemicals. Environ Chem Lett 12:85-95 (2014).

4. Riederer M and Friedmann A, Transport of lipophilic non-electrolytes across the cuticle. Annual Plant Reviews 23:250-279 (2008).

5. Chollet JF, Rocher F, Jousse C, Deletage-Grandon C, Bashiardes G and Bonnemain JL, Acidic derivatives of the fungicide fenpiclonil: effect of adding a methyl group to the $\mathrm{N}$-substituted chain on systemicity and fungicidal activity. Pest Manage Sci 61:377-382 (2005).

6. Bromilow RH, Chamberlain K and Evans AA. Molecular structure and properties of xenobiotics in relation to phloem translocation. In Recent advances in phloem transport and assimilate compartmentation; Fourth International Conference on Phloem Transport and Assimilate Compartmentation, Cognac, France, August 19-24, 1990, ed. by Bonnemain JL, Delrot S, Lucas WJ and Dainty J. Ouest Editions: Nantes, France, pp. 332-340 (1991).

7. Kleier DA and Hsu FC, Phloem mobility of xenobiotics. VII. The design of phloem systemic pesticides. Weed Sci 44:749-756 (1996).

8. Jeschke P, Propesticides and their use as agrochemicals. Pest Manage Sci 72:210-225 (2016).

9. Delétage-Grandon C, Chollet JF, Faucher M, Rocher F, Komor E and Bonnemain JL, Carrier-mediated uptake and phloem systemy of a 350-dalton chlorinated xenobiotic with an alpha-amino acid function. Plant Physiol 125:1620-1632 (2001).

10. You G and Morris ME. Overview of drug transporter families. In Drug transporters: molecular characterization and role in drug disposition, 2nd edition, ed. by You G and Morris ME. J. Wiley \& Sons Inc., pp. 1-6 (2014).

11. DeGorter MK, Xia CQ, Yang JJ and Kim RB. Drug transporters in drug efficacy and toxicity. In Annual Review of Pharmacology and Toxicology, Vol 52, ed. by Insel PA, Amara SG and Blaschke TF. Annual Reviews: Palo Alto, pp. 249-273 (2012).

12. Zawilska JB, Wojcieszak J and Olejniczak AB, Prodrugs: A challenge for the drug development. Pharmacol Rep 65:1-14 (2013).

13. Giacomini KM, Huang S-MM, Tweedie DJ, Benet LZ, Brouwer KLR, Chu X, Dahlin A, Evers R, Fischer V, Hillgren KM, Hoffmaster KA, Ishikawa T, Keppler D, Kim RB, Lee Ca, Niemi M, Polli JW, Sugiyama Y, Swaan PW, Ware Ja, Wright SH, Yee SW, Zamek-Gliszczynski MJ and Zhang L, Membrane transporters in drug development. Nat Rev Drug Discov 9:215-236 (2010).

14. Pardridge WM, Drug transport across the blood-brain barrier. J Cereb Blood Flow Metab 32:1959-1972 (2012). 
15. Varma MV, Ambler CM, Ullah M, Rotter CJ, Sun H, Litchfield J, Fenner KS and El-Kattan AF, Targeting intestinal transporters for optimizing oral drug absorption. Curr Drug Metab 11:730-742 (2010).

16. del Amo EM, Urtti A and Yliperttula M, Pharmacokinetic role of L-type amino acid transporters LAT1 and LAT2. Eur J Pharm Sci 35:161-174 (2008).

17. Rautio J, Laine K, Gynther M and Savolainen J, Prodrug approaches for CNS delivery. AAPS J 10:92102 (2008).

18. de Vrueh RL, Smith PL and Lee CP, Transport of L-valine-acyclovir via the oligopeptide transporter in the human intestinal cell line, Caco-2. J Pharmacol Exp Ther 286:1166-1170 (1998).

19. Jung D and Dorr A, Single-dose pharmacokinetics of valganciclovir in HIV- and CMV-seropositive subjects. J Clin Pharmacol 39:800-804 (2013).

20. Gynther M, Jalkanen A, Lehtonen M, Forsberg M, Laine K, Ropponen J, Leppänen J, Knuuti J and Rautio J, Brain uptake of ketoprofen-lysine prodrug in rats. Int J Pharm 399:121-128 (2010).

21. Casida JE, Why prodrugs and propesticides succeed. Chem Res Toxicol 30:1117-1126 (2017).

22. Salgado VL and David MD, Chance and design in proinsecticide discovery. Pest Manage Sci 73:723730 (2017).

23. Hsu FC and Kleier DA, Phloem mobility of xenobiotics VIII. A short review. J Exp Bot 47 Spec No:1265-1271 (1996).

24. Zhang Y, Lorsbach BA, Castetter S, Lambert WT, Kister J, Wang NX, Klittich CJR, Roth J, Sparks TC and Loso MR, Physicochemical property guidelines for modern agrochemicals. Pest Manage Sci 74:1979-1991 (2018).

25. Park J, Lee Y, Martinoia E and Geisler M, Plant hormone transporters: what we know and what we would like to know. BMC Biol 15:93 (2017).

26. Do THT, Martinoia E and Lee Y, Functions of ABC transporters in plant growth and development. Curr Opin Plant Biol 41:32-38 (2018).

27. Kuhn C and Grof CPL, Sucrose transporters of higher plants. Curr Opin Plant Biol 13:287-298 (2010).

28. Judy A. Gougler DRG, Uptake and distribution of N-Phosphonomethylglycine in sugar beet plants. Plant Physiol 68:668-672 (1981).

29. Denis M-H and Delrot S, Carrier-mediated uptake of glyphosate in broad bean (Vicia faba) via a phosphate transporter. Physiol Plant 87:569-575 (1993).

30. Hetherington PR, Marshall G, Kirkwood RC and Warner JM, Absorption and efflux of glyphosate by cell suspensions. J Exp Bot 49:527-533 (1998).

31. Shaner DL, Role of translocation as a mechanism of resistance to glyphosate. Weed Sci 57:118-123 (2009).

32. Xu J, Li G, Wang Z, Si L, He S, Cai J, Huang J and Donovan MD, The role of L-type amino acid transporters in the uptake of glyphosate across mammalian epithelial tissues. Chemosphere 145:487-494 (2016).

33. Leconte F, Bonnemain JL, Decormis L and Barchietto T, Metabolic fate, compartmentation and forms of transport (xylem and phloem mobility) of fosethyl-Al in Lycopersicon-esculentum Mill. C R Acad Sci, Ser III Sci Vie/Life Sci 307:221-227 (1988).

34. Achary VMM, Ram B, Manna M, Datta D, Bhatt A, Reddy MK and Agrawal PK, Phosphite: a novel P fertilizer for weed management and pathogen control. Plant Biotechnol J 15:1493-1508 (2017).

35. Hart JJ, Ditomaso JM, Linscott DL and Kochian LV, Transport interactions between paraquat and polyamines in roots of intact maize seedlings. Plant Physiol 99:1400-1405 (1992).

36. Fujita M, Fujita Y, Iuchi S, Yamada K, Kobayashi Y, Urano K, Kobayashi M, Yamaguchi-Shinozaki K and Shinozaki K, Natural variation in a polyamine transporter determines paraquat tolerance in Arabidopsis. Proc Natl Acad Sci USA 109:6343-6347 (2012). 
37. Xi J, Xu P and Xiang CB, Loss of AtPDR11, a plasma membrane-localized ABC transporter, confers paraquat tolerance in Arabidopsis thaliana. Plant J 69:782-791 (2012).

38. Kasai F and Bayer DE, Effects of 2,4-dichlorophenoxyacetic acid, antiauxins, and metabolic perturbations on cytoplasmic and vacuolar $\mathrm{pH}$ of corn root tips measured by in vivo 31P-NMR. Pestic Biochem Physiol 51:161-169 (1995).

39. Chen L, Ortiz-Lopez a, Jung a and Bush DR, ANT1, an aromatic and neutral amino acid transporter in Arabidopsis. Plant Physiol 125:1813-1820 (2001).

40. Brück E, Elbert A, Fischer R, Krueger S, Kühnhold J, Klueken aM, Nauen R, Niebes JF, Reckmann U, Schnorbach HJ, Steffens R and van Waetermeulen X, Movento ${ }^{\circledR}$, an innovative ambimobile insecticide for sucking insect pest control in agriculture: Biological profile and field performance. Crop Protect 28:838-844 (2009).

41. Zhivotovsky Castello O, Bowling AJ, Deboer G and Adelfinskaya Y, Assessment of phloem mobility of xenobiotics in Triticum aestivum and Brachypodium distachyon. Funct Plant Biol 41:598 (2014).

42. Bromilow RH, Chamberlain K and Evans AA, Physicochemical aspects of phloem translocation of herbicides. Weed Sci 38:305-314 (1990).

43. Satchivi NM, Stoller EW, Wax LM and Briskin DP, A nonlinear, dynamic, simulation model for transport, and whole plant allocation of systemic xenobiotics following foliar application. IV: Physicochemical properties requirements for optimum absorption and translocation. Pestic Biochem Physiol 84:83-97 (2006).

44. Lipinski CA, Lombardo F, Dominy BW and Feeney PJ, Experimental and computational approaches to estimate solubility and permeability in drug discovery and development settings. Adv Drug Del Rev 23:3-25 (1997).

45. Veber DF, Johnson SR, Cheng HY, Smith BR, Ward KW and Kopple KD, Molecular properties that influence the oral bioavailability of drug candidates. J Med Chem 45:2615-2623 (2002).

46. Tice CM, Selecting the right compounds for screening: does Lipinski's Rule of 5 for pharmaceuticals apply to agrochemicals? Pest Manage Sci 57:3-16 (2001).

47. Avram S, Funar-timofei S, Borota A, Chennamaneni SR and Manchala AK, Quantitative estimation of pesticide-likeness for agrochemical discovery. J Cheminform 6:42 (2014).

48. Wu HX, Yang W, Zhang ZX, Huang T, Yao GK and Xu HH, Uptake and phloem transport of glucosefipronil conjugate in Ricinus communis involve a carrier-mediated mechanism. J Agric Food Chem 60:60886094 (2012).

49. Rocher F, Chollet JF, Legros S, Jousse C, Lemoine R, Faucher M, Bush DR and Bonnemain JL, Salicylic acid transport in Ricinus communis involves a pH-dependent carrier system in addition to diffusion. Plant Physiol 150:2081-2091 (2009).

50. Chollet JF, Delétage C, Faucher M, Miginiac L and Bonnemain JL, Synthesis and structure-activity relationships of some pesticides with an alpha-amino acid function. Biochim Biophys Acta 1336:331-341 (1997).

51. Magnus V, Nigovic B, Hangarter RP and Good NE, N-(Indol-3-ylacetyl)amino acids as sources of auxin in plant tissue culture. J Plant Growth Regul 11:19-28 (1992).

52. Dufaud A, Chollet JF, Rudelle J, Miginiac L and Bonnemain JL, Derivatives of pesticides with an alpha-amino acid function: synthesis and effect on threonine uptake. Pestic Sci 41:297-304 (1994).

53. Rocher F. Lutte chimique contre les champignons pathogènes des plantes : évaluation de la systémie phloémienne de nouvelles molécules à effet fongicide et d'activateurs de réactions de défense. PhD, Université de Poitiers, Poitiers, (2004).

54. Wu H, Marhadour S, Lei Z-W, Yang W, Marivingt-Mounir C, Bonnemain J-L and Chollet J-F, Vectorization of agrochemicals: amino acid carriers are more efficient than sugar carriers to translocate phenylpyrrole conjugates in the Ricinus system. Environ Sci Pollut Res 25:14336-14349 (2018). 
55. Marhadour S, Wu H, Yang W, Marivingt-Mounir C, Bonnemain J-L and Chollet J-F, Vectorisation of agrochemicals via amino acid carriers: influence of the spacer arm structure on the phloem mobility of phenylpyrrole conjugates in the Ricinus system. Pest Manage Sci 73:1972-1982 (2017).

56. Wu H, Marhadour S, Lei ZW, Dugaro E, Gaillard C, Porcheron B, Marivingt-Mounir C, Lemoine R, Chollet JF and Bonnemain JL, Use of D-glucose-fenpiclonil conjugate as a potent and specific inhibitor of sucrose carriers. $J$ Exp Bot 68:5599-5613 (2017).

57. Xu HH, Jiang, D. X., Hu, S., Zhang, X. W. Synthesis of guided pesticide and their biological activities. In 11th IUPAC International Congress of Pesticide Chemistry: Kobe, Japan (2006).

58. Jiang DX, Lu XL, Hu S, Zhang XB and Xu HH, A new derivative of fipronil: Effect of adding a glycinyl group to the 5-amine of pyrazole on phloem mobility and insecticidal activity. Pestic Biochem Physiol 95:126-130 (2009).

59. Yuan JG, Wu HX, Lu ML, Song GP and Xu HH, Synthesis of a series of monosaccharide-fipronil conjugates and their phloem mobility. J Agric Food Chem 61:4236-4241 (2013).

60. Wang J, Lei Z, Wen Y, Mao G, Wu $\mathrm{H}$ and $\mathrm{Xu} \mathrm{H}$, A novel fluorescent conjugate applicable to visualize the translocation of glucose-fipronil. J Agric Food Chem 62:8791-8798 (2014).

61. Qin PW, Wang J, Wang H, Wen YJ, Lu ML, Li YF, Xu YS and Xu HH, Synthesis of rotenone-Omonosaccharide derivatives and their phloem mobility. J Agric Food Chem 62:4521-4527 (2014).

62. Xie Y, Zhao JL, Wang CW, Yu AX, Liu N, Chen L, Lin F and Xu HH, Glycinergic-fipronil uptake is mediated by an amino acid carrier system and induces the expression of amino acid transporter genes in Ricinus communis seedlings. J Agric Food Chem 64:3810-3818 (2016).

63. Yao G, Wen Y, Zhao $\mathrm{C}$ and $\mathrm{Xu} \mathrm{H}$, Novel amino acid ester-chlorantraniliprole conjugates: design, synthesis, phloem accumulation and bioactivity. Pest Manage Sci 73:2131-2137 (2017).

64. Coleman JOD, BlakeKalff MMA and Davies TGE, Detoxification of xenobiotics by plants: Chemical modification and vacuolar compartmentation. Trends Plant Sci 2:144-151 (1997).

65. Xia Q, Wen YJ, Wang H, Li YF and Xu HH, $\beta$-Glucosidase involvement in the bioactivation of glycosyl conjugates in plants: synthesis and metabolism of four glycosidic bond conjugates in vitro and in vivo. J Agric Food Chem 62:11037-11046 (2014).

66. Wen Y, Jiang X, Yang C, Meng H, Wang B, Wu H, Zhang Z and Xu H, The linker length of glucosefipronil conjugates has a major effect on the rate of bioactivation by $\beta$-glucosidase. Pest Manage Sci:In press, doi:10.1002/ps.5170 (2018).

67. De Moliner F, Knox K, Reinders A, Ward JM, McLaughlin PJ, Oparka K and Vendrell M, Probing binding specificity of the sucrose transporter AtSUC2 with fluorescent coumarin glucosides. J Exp Bot 69:24732482 (2018).

68. Jiang X, Xie Y, Ren Z, Ganeteg U, Lin F, Zhao C and Xu H, Design of a new glutamine-fipronil conjugate with $\alpha$-amino acid function and its uptake by $A$. thaliana lysine histidine transporter 1 (AtLHT1). $J$ Agric Food Chem 2018).

69. Mao GL, Yan Y, Chen Y, Wang BF, Xu FF, Zhang ZX, Lin F and Xu HH, Family of Ricinus communis monosaccharide transporters and RcSTP1 in promoting the uptake of a glucose-fipronil conjugate. J Agric Food Chem 65:6169-6178 (2017).

70. Chen Y, Lei ZW, Zhang Y, Yang W, Liu HF, Zhou YF and Yang MF, Influence of pyranose and spacer arm structures on phloem mobility and insecticidal activity of new tralopyril derivatives. Molecules 22:1058 (2017).

71. Larsen B, Xu D, Halkier BA and Nour-Eldin HH, Advances in methods for identification and characterization of plant transporter function. $J$ Exp Bot 68:4045-4056 (2017). 
72. Matsson $\mathrm{P}$ and Bergstrom CA, Computational modeling to predict the functions and impact of drug transporters. In Silico Pharmacol 3:8 (2015).

73. Jorgensen ME, Xu D, Crocoll C, Ramírez D, Motawia MS, Olsen CE, Nour-Eldin HH and Halkier BA, Origin and evolution of transporter substrate specificity within the NPF family. ELife 6:e19466 (2017).

74. Metraux JP, Signer H, Ryals J, Ward E, Wyss-Benz M, Gaudin J, Raschdorf K, Schmid E, Blum W and Inverardi $\mathrm{B}$, Increase in salicylic acid at the onset of systemic acquired resistance in cucumber. Science 250:1004-1006 (1990).

75. Dean JV, Mohammed LA and Fitzpatrick T, The formation, vacuolar localization, and tonoplast transport of salicylic acid glucose conjugates in tobacco cell suspension cultures. Planta 221:287-296 (2005).

76. Bonnemain JL, Chollet JF and Rocher F. Transport of Salicylic Acid and Related Compounds. In Salicylic acid, Plant growth and development, ed. by Hayat S, Ahmad A and Alyemeni MN. Springer Netherlands, pp. 43-59 (2013).

77. Shulaev V, Leon J and Raskin I, Is salicylic acid a translocated signal of systemic acquired resistance in tobacco? Plant Cell 7:1691-1701 (1995).

78. Noutoshi Y, Jikumaru Y, Kamiya Y and Shirasu K, ImprimatinC1, a novel plant immune-priming compound, functions as a partial agonist of salicylic acid. Sci rep 2:705 (2012). 
Table 1 Structure and physicochemical properties of carboxylic acid derivatives (A-D phenoxyacetic acids; E phenoxybutyric acid; F salicylic acid; G 3,5-dichlorobenzoic acid) coupled with L-lysine. All properties were computed using ACD Log D Sol Suite v.14.02 software.

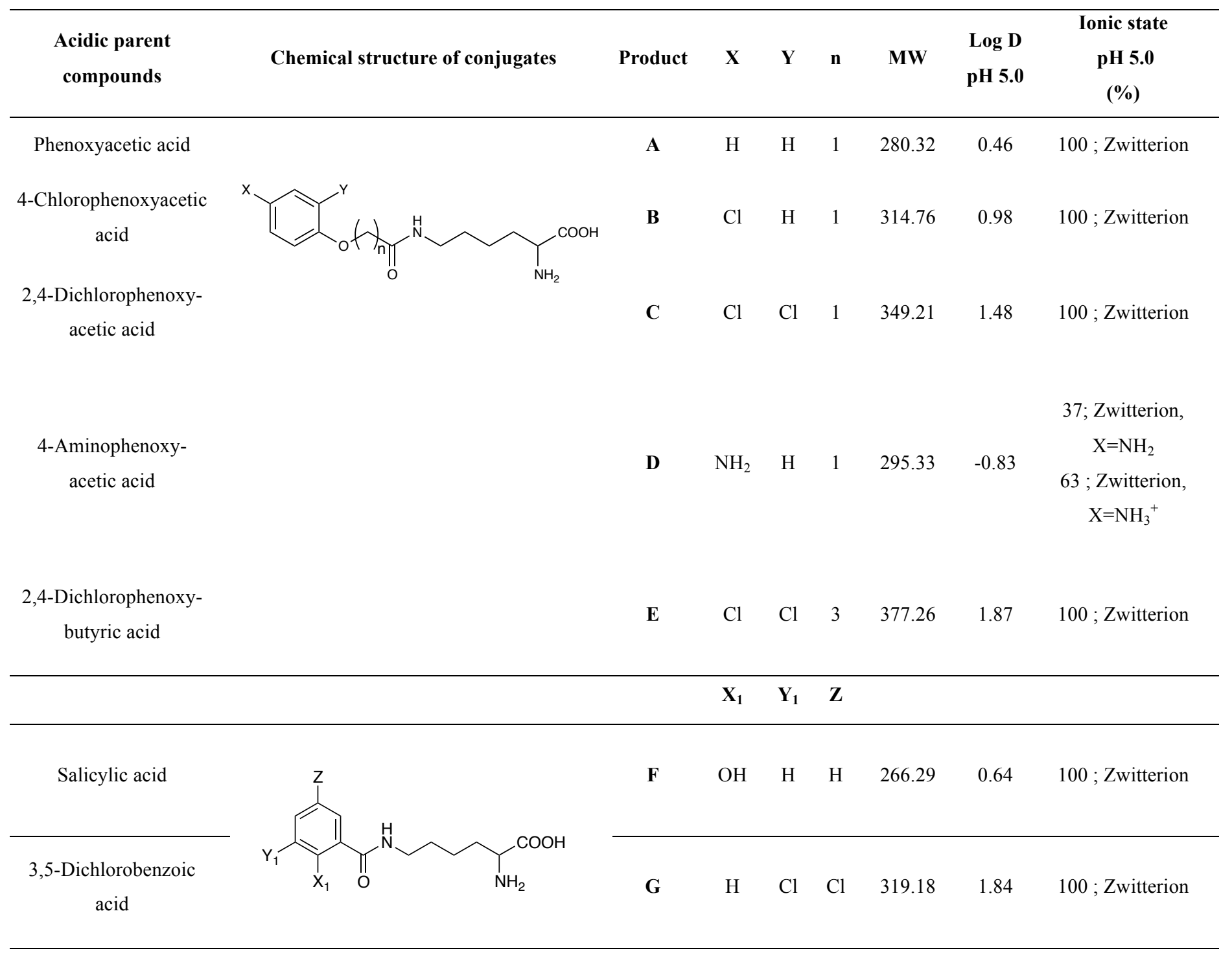


Table 2 Main endogenous moiety-pesticide conjugates tested for phloem systemicity. MW: molecular weight; Concentration factor $(\mathrm{CF})=$ Concentration in phloem sap / Concentration in the incubation solution; NS : not studied; * enzymatic hydrolysis by $ß$-glucosidase in vitro and in vivo; $\uparrow$ release the parent compound in adult Ricinus

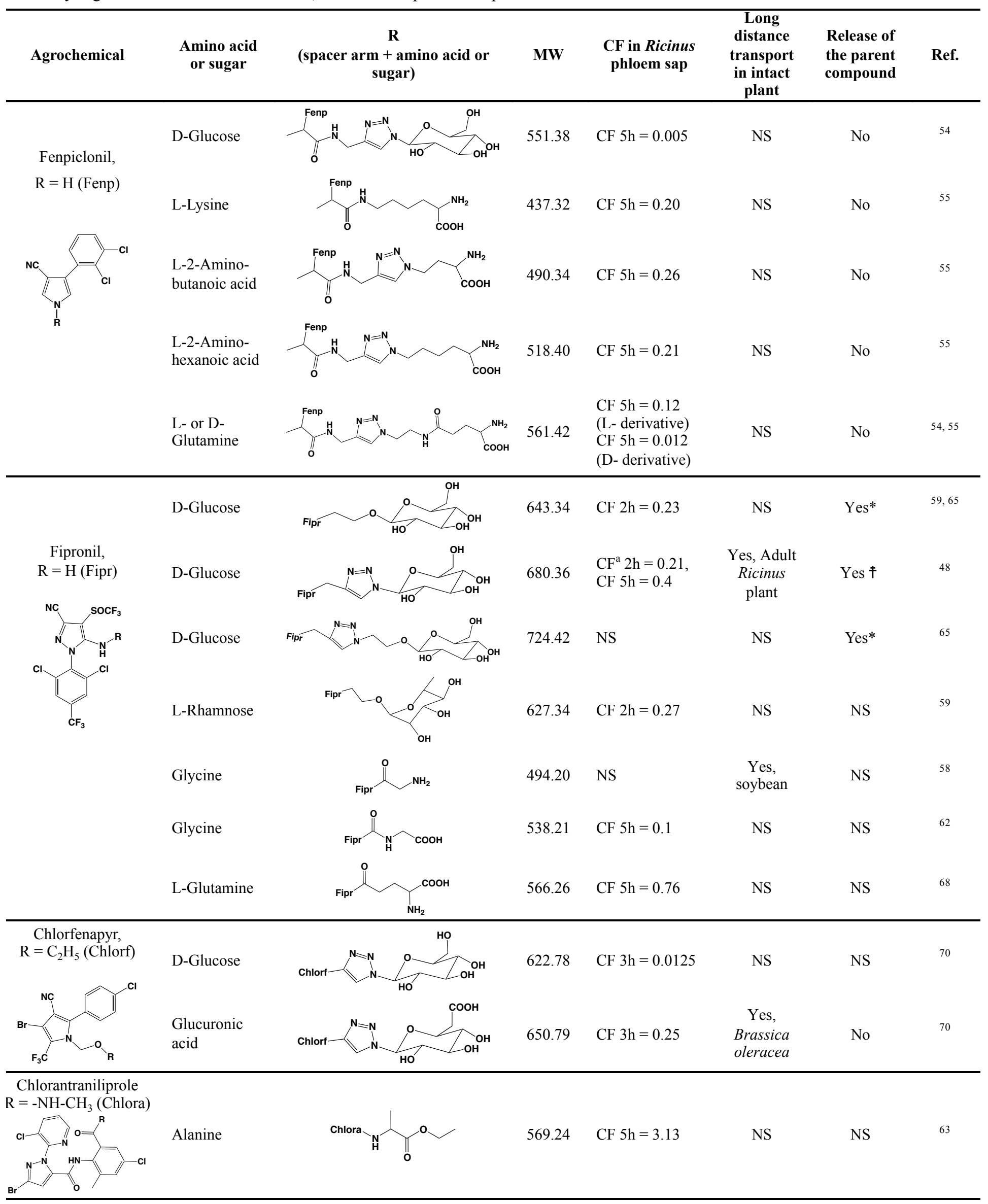




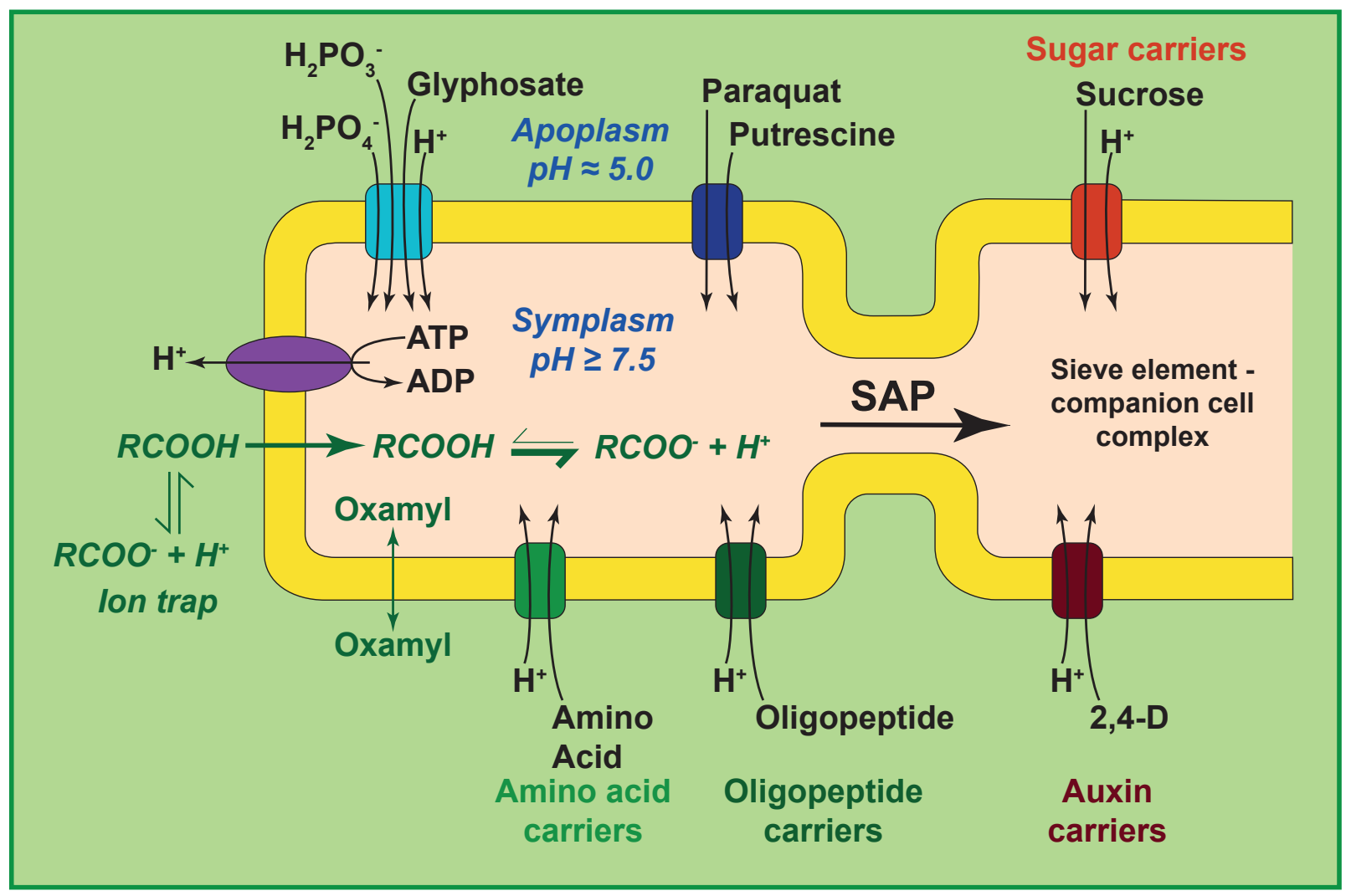

Figure 1. Illustration of different possible pathways involved in the uptake of xenobiotics by the phloem tissue (apoplastic loading) (adapted from Delétage-Grandon et al, 2001) 


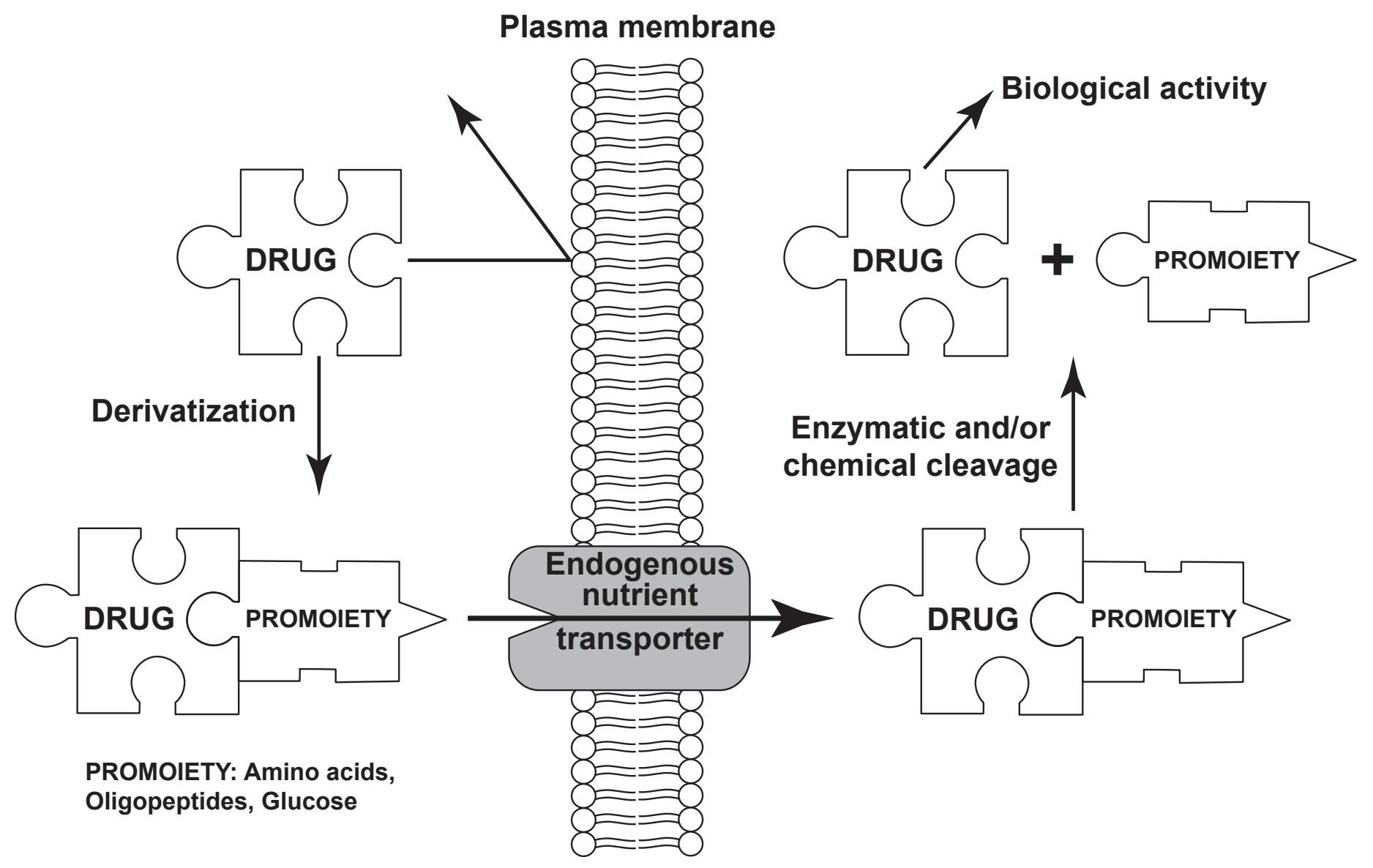

Figure 2. A representative illustration of the prodrug concept that has been also used for agrochemicals. (adapted from Rautio et al, 2008) ${ }^{17}$ 


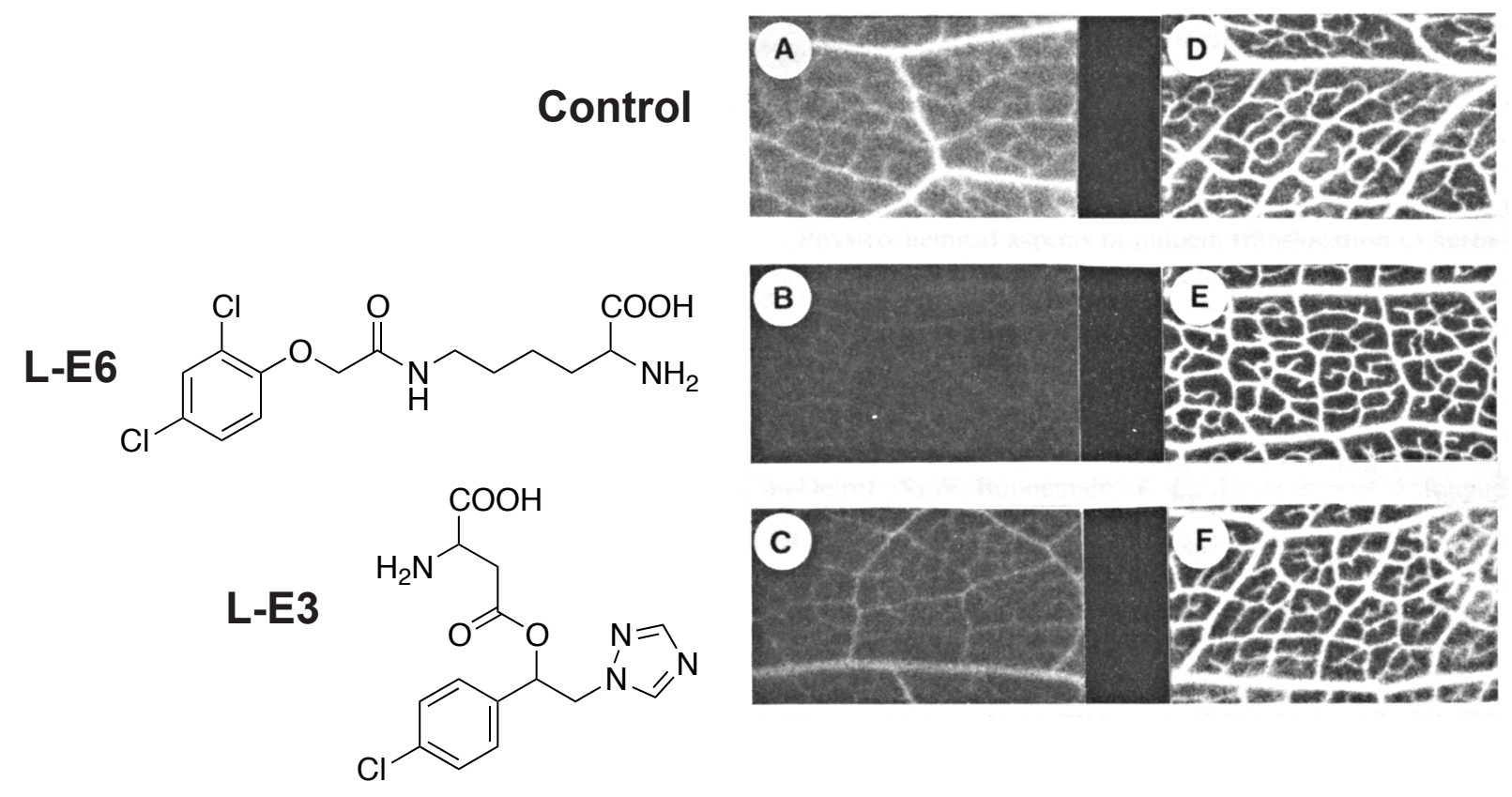

Figure 3. Selective inhibition of amino acid uptake by two agrochemical-amino acid conjugates. Autoradiographs showing the effect of L-E6 and L-E3 conjugates on $1 \mathrm{mM}\left[\mathrm{U}-{ }^{14} \mathrm{C}\right]$ L-threonine uptake $(A, B, C)$ or on $1 \mathrm{mM}\left[\mathrm{U}-{ }^{14} \mathrm{C}\right]$ sucrose uptake $(\mathrm{D}, \mathrm{E}, \mathrm{F})$ by broad-bean leaf tissues. $B$ and $E$ : $2.5 \mathrm{mM} \mathrm{L-E6} \mathrm{;} \mathrm{C} \mathrm{and} \mathrm{F} \mathrm{:} 2$ mM L-E3. The radioactivity appears in white. Tissues are shown at $7 \mathrm{X}$ magnification. (from Dufaud et al, 1994) ${ }^{52}$ 


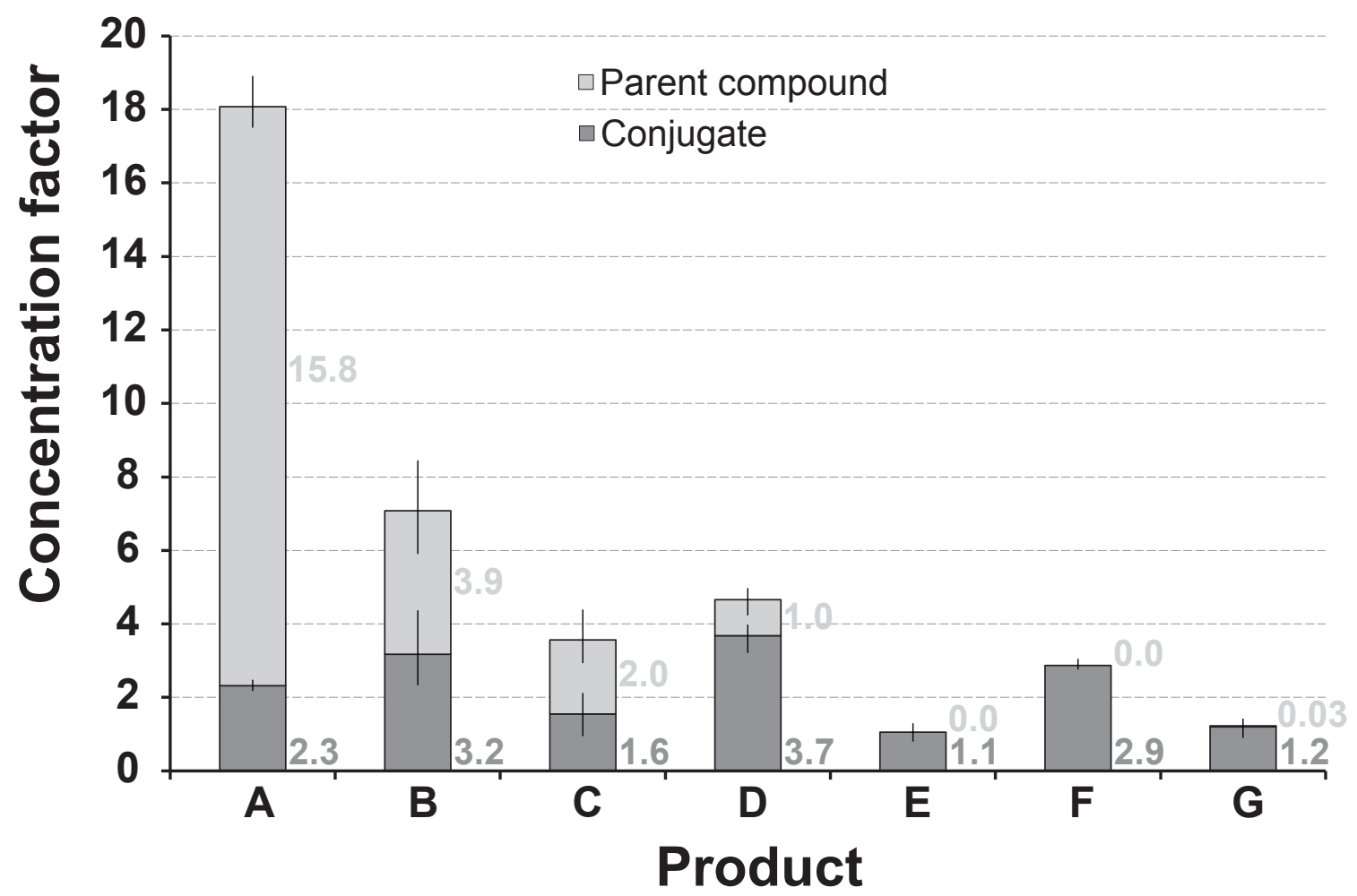

Figure 4. Phloem exudation of various agrochemical-amino acid conjugates and their respective parent compound using the Ricinus model. Concentration factors of Lys-phenoxyacetic acid (A), Lys-4-chlorophenoxyacetic acid (B), Lys-2,4-dichlorophenoxyacetic acid (C), Lys-4-aminophenoxyacetic acid (D), Lys-2,4-dichlorophenoxybutyric acid (E), Lys-salicylic acid (F) and Lys-3,5-dichlorobenzoic acid (G) (dark grey bars) and their respective parent compound (light grey stacked bars) in the Ricinus phloem sap. The conjugates were added to the incubation medium of cotyledons at $0.1 \mathrm{mM}$ except for $\mathrm{D}$ which was used at $0.5 \mathrm{mM}$, final concentration, $\mathrm{pH}$ 5.0. The sap was collected from hypocotyl during the third and the fourth hours of cotyledon incubation. The concentration factor was defined as the ratio of the concentration of product in phloem sap / the initial concentration in incubation medium. Medians $\pm I Q R, 8 \leq n \leq 12$. (Rocher et al., $2004)^{53}$. 